Article

\title{
Screening of Carbamate and Organophosphate Pesticides in Food Matrices Using an Affordable and Simple Spectrophotometric Acetylcholinesterase Assay
}

\author{
Aristeidis S. Tsagkaris $@$, Leos Uttl, Jana Pulkrabova $@$ and Jana Hajslova* \\ Department of Food Analysis and Nutrition, Faculty of Food and Biochemical Technology, University of \\ Chemistry and Technology Prague, Technická 5, 16628 Prague 6- Dejvice, Prague, Czech Republic; \\ tsagkara@vscht.cz (A.S.T.); uttll@vscht.cz (L.U.); pulkrabj@vscht.cz (J.P.) \\ * Correspondence: jana.hajslova@vscht.cz; Tel.: +420-220-443-185
}

Received: 3 December 2019; Accepted: 9 January 2020; Published: 13 January 2020

\begin{abstract}
Carbamates (CMs) and organophosphates (OPs) are widely used pesticides with known neurotoxicity arising from the inhibition of acetylcholinesterase (AChE). When AChE is active, in vitro, it can hydrolyze certain substrates to colored products while in the presence of an inhibitor this color development is decreased. Based on this principle, an AChE assay for CM and OP compounds was optimized and validated for carbofuran, carbofuran-3-hydroxy and dichlorvos in lettuce and strawberry extracts. The analytical performance of the assay was confirmed by an accredited liquid chromatography tandem mass spectrometry (LC-MS/MS) method. The developed AChE assay achieved low limits of detection (LODs) at the part per billion (ppb) level, depending the analyte inhibitory strength, recovery rates higher than $70 \%$ and good repeatability. Moreover, the toxic unit (TU) approach was applied, for extracts containing the validated analytes, and antagonism was noticed in all cases. Overall, the developed method is rapid, simple, cost-effective and may find application as a low-cost pre-screening tool of AChE inhibitors presence. Last but not least, this study can be considered a guide on development, validation and benchmarking of bioassays in food safety, a topic, which is commonly mispresented in the available literature.
\end{abstract}

Keywords: carbamates; organophosphates; pesticides; acetylcholinesterase; food; screening method; microwell-plate assay; liquid chromatography tandem mass spectrometry

\section{Introduction}

The ever-increasing demand for food production requires a widespread use of pesticides to prevent pests and boost agricultural productivity. Pesticides encompass a numerous and diverse group of chemical compounds that can be used to combat a wide variety of pests. Regarding insecticides, carbamates (CMs) and organophosphates (OPs) are commonly utilized because, compared to old-school organochlorines (OCs), they do not usually release toxic metabolites and are less persistent in the environment [1]. However, CMs and OPs show relatively high acute toxicity and their residues in food may result in chronic toxicity incidents [2].

The toxicity of CMs and OPs arises from the inhibition of acetylcholinesterase (AChE), a vital enzyme in the neural system of insects and mammals including humans. Typically, AChE hydrolyzes the neurotransmitter acetylcholine into choline and acetic acid (Figure 1a), an essential reaction that enables the cholinergic neuron to return to its resting state after activation. However, AChE activity is reduced in the presence of CMs or OPs, due to carbamylation or phosphorylation of serine hydroxyl group in the enzyme active cite [3], respectively. This results in acetylcholine accumulation, which can 
lead, in case of higher exposure, to health problems, including bradycardia, salivation, diarrhea or even coma [4]. A complete overview on AChE physiological function and inhibition mechanisms published by Miao et al. [5] may provide a deeper understanding of the issue. Clearly, there is an urgent need to develop sensitive and accurate analytical methods for OPs and CMs detection considering their impact on health and the potential of dietary exposure as this was reflected in the latest European Food Safety Authority (EFSA) report on pesticides [6] and the EFSA pesticide residue intake model (PRIMo) [7].

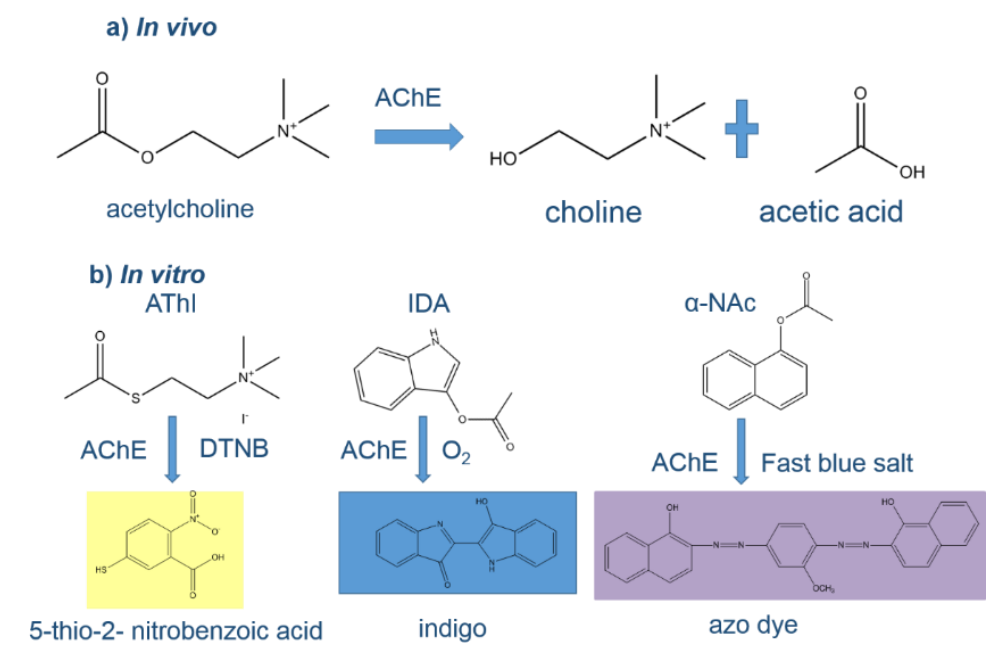

Figure 1. (a) In vivo, the neurotransmitter acetylcholine is hydrolyzed to choline and acetic acid by $\mathrm{AChE}$; (b) in vitro hydrolysis of various substrates (acetylthiocholine iodide (AThI, Ellman's assay substrate), indoxyl acetate (IDA) and $\alpha$-naphthyl acetate ( $\alpha$-NAc)) by AChE producing different colored products.

Liquid and/or gas chromatography tandem mass spectrometry (LC-MS/MS and/or GC-MS/MS) are commonly applied for pesticide residues monitoring in food matrices [8]. Although these methods provide selectivity, sensitivity with high-throughput capabilities, LC/MS and GC/MS are also costly and time-consuming methodologies that require skilled personnel [9]. To counter these limitations, an ever-increased use of sensor-based methods has been noticed [10]. Various immunoassays were developed against specific CMs and OPs [11,12]. Although this approach may be even more sensitive than chromatographic methods, it detects one or only a limited number of pesticides. Regarding electrochemical (EC) sensors, there were several studies using both enzymatic [13] and non-enzymatic pesticide recognition [14] employing different EC principles, such as amperometry [15] and voltammetry [16]. Despite reaching low limits of detection (LODs), mostly in buffers, these methods suffered from complicated manufacturing and problematic storage stability period [17]. Considering optical detection, surface-enhanced Raman spectroscopy (SERS), surface plasmon resonance (SPR) and spectroscopic methods have been used. SERS has been emerged as an attractive analytical choice due to its portability potential. However, pesticides detection only on fruit peels [18] was a major weakness limiting its application. Although SPR and fluorescent methods showed promising results, especially when combined with nanomaterials (NMs) [19], their sophisticated analytical configuration comes in contrast to the need for simplified alternative methods.

$\mathrm{AChE}$ assays may be considered as a potential solution for the aforementioned analytical needs. These assays are based on the principle that the enzyme, in vitro, can produce a colored product (Figure $1 b$ ). Under relevant conditions, in the presence of an analyte the residual AChE activity (meaning less color production) can be correlated to an inhibitor concentration by comparing this response with a control sample. The simplest way to monitor this color development is by using an absorption spectroscopy reader, which is a cost efficient, reliable and semi-portable (it fits into a backpack) detector. This principle can be applied for the rapid monitoring of CMs and OPs in food 
extracts providing high throughput, when using a 96-microwell plate, minimum reagents consumption and LODs at the ppb level, depending on the matrix [20,21].

In this study, the development and validation of an AChE assay for CM and OP pesticides is presented. During assay optimization, various parameters were investigated including a critical comparison of commonly applied AChE substrates for the first time. Following our recently published paper, which addressed the issues related to the validation and benchmarking of biosensors in food safety [8], comprehensive validation datasets for carbofuran, carbofuran-3-hydroxy and dichlorvos in strawberry and lettuce extracts are presented. The optimized AChE assay was benchmarked towards an accredited LC-MS/MS method, following the regulatory requirement (Decision 2002/657/EC) of confirming bioassays results with an instrumental method.

\section{Materials and Methods}

\subsection{Chemicals}

Phosphate buffer saline (PBS) tablets, AChE from Electrophorus electricus, acetylthiocholine iodide (AThI, purity $>99 \%$ ), 5,5'-dithio bis-2-nitrobenzoic acid (DTNB, purity $>99 \%$ ) indoxyl acetate (IDA, purity $>95 \%$ ), a-naphthyl acetate ( $\alpha$-NAc, purity $>98 \%$ ), fast blue B salt (FBBS, purity $95 \%$ ), z-sep sorbent, $0.22 \mu \mathrm{m}$ syringe filters, $5 \mathrm{~mL}$ syringes were from Sigma-Aldrich (Prague, Czech Republic). 96-microwell plates were supplied by Gama Group (Ceske Budejovice, Czech Republic). Acetylcholinesterase stock

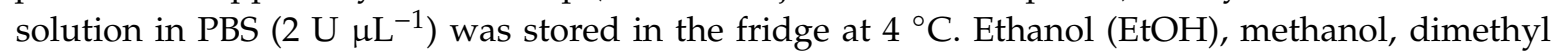
sulfoxide, acetonitrile and ethyl acetate were supplied as high purity solvents from Merck (Darmstadt, Germany) and Supelco (Bellefonte, PA, USA). Triphenyl phosphate (TPP), ammonium formate ( $\geq 99 \%)$ and formic acid and were from Sigma-Aldrich (Taufkirchen, Germany). Anhydrous magnesium sulphate (MgSO4) was obtained from Fluka (Buchs, Germany), and sodium chloride ( $\mathrm{NaCl}$ ) from Penta (Chrudim, Czech Republic). Sorbent primary-secondary amine (PSA, Bondesil, $40 \mu \mathrm{m}$ ) was purchased from Agilent Technologies (USA). Deionized water was purified using a Milli-Q system (Millipore; Bedford, MA, USA). Aldicarb, carbofuran, carbofuran-3-hydroxy, carbaryl, dichlorvos, chlorpyrifos and paraoxon standards were of analytical standard grade and purchased by Sigma Aldrich (Taufkirchen, Germany). Malathion (purity 99\%), malaoxon (purity 99\%) and parathion (purity 99\%) were bought by Dr. Ehrenstorfer GmbH (Augsburg, Germany). Chlorpyrifos-oxon was of analytical standard grade and supplied by Labicom (Olomouc, Czech Republic). Pesticides stock solutions $\left(3.0 \mathrm{mg} \mathrm{mL}^{-1}\right)$ were prepared in acetonitrile and kept in a freezer at $-20{ }^{\circ} \mathrm{C}$ protected from ambient light. Pesticides working solutions were daily prepared in PBS-EtOH (7:3, v/v).

\subsection{In Vitro AChE Assays}

Ellman's [22], IDA [23] and $\alpha$-NAc [24] assays were tested to choose which one fits better for the analytical purpose. In all cases, the experimental protocols were modified and transmitted the assay to a microwell plate format. Briefly, in all assays the enzyme was incubated with an inhibitor for $15 \mathrm{~min}$, followed by a substrate addition and absorbance measurement in an Epoch Biotek Reader (Vermont, USA). Assay protocols are further explained in the Supplementary Materials.

The experiments were performed in three independent days, in triplicate and the data were pooled ( $n=9$ for each calibration point). To obtain the $20 \%$ of the maximal and half maximal inhibitory concentration ( $\mathrm{IC}_{20}$ and $\mathrm{IC}_{50}$, respectively), a pesticide was prepared in seven different concentration levels (Table S1) and compared to a control sample. Dose-response with variable slope analysis was performed using GraphPad prism 5.0 software. More information on the four-parameter dose-response model can be found in [25].

\subsection{AChE Assay Specificity}

CMs and OPs have the same mode of action towards AChE, thus, it is important to evaluate AChE specificity towards the tested inhibitors. Assay specificity was evaluated in terms of cross-reactivity 
towards carbofuran, which was the strongest AChE inhibitor (see Section 3.1.2). The cross-reactivity was calculated as follows:

Cross-reactivity $(\%)=\left(\mathrm{IC}_{50}\right.$ carbofuran $/ \mathrm{IC}_{50}$ pesticide $) \times 100$, carbofuran cross-reactivity was set as $100 \%$.

\subsection{Food Samples}

Strawberry and lettuce bio-samples were purchased by the local market. A representative portion was homogenized with a PM-100 Retsch Planetary Ball Mill (Haan, Germany) and the samples were kept at $-20{ }^{\circ} \mathrm{C}$. Prior to the enzyme assay, the samples were analyzed by an LC-MS/MS method to verify that they did not contain detectable levels of OPs and CMs.

\subsection{Food Samples Extraction}

A modified ethyl acetate extraction [26] followed by a dispersive clean up-step using a zirconium based sorbent (z-sep) was developed to process strawberry and lettuce samples. In detail, $10 \mathrm{~g}$ of homogenized samples were weighed into a $50 \mathrm{~mL}$ polypropylene tube. When needed, samples were spiked with target analytes from a freshly prepared solution $\left(20 \mu \mathrm{g} \mathrm{mL}^{-1}\right)$ to achieve the final concentration and left for at least $30 \mathrm{~min}$ at room temperature. Afterwards, $10 \mathrm{~mL}$ of ethyl acetate were added and tubes were shaken vigorously for $2 \mathrm{~min}$ with hands, followed by the addition of $10 \mathrm{~g}$ of $\mathrm{Na}_{2} \mathrm{SO}_{4}$ and the tubes were shaken for $30 \mathrm{~s}$. Then, $2 \mathrm{~mL}$ from the supernatant were transferred to a $15 \mathrm{~mL}$ polypropylene tube containing $65 \mathrm{mg}$ z-sep and $300 \mathrm{mg} \mathrm{Na}_{2} \mathrm{SO}_{4}$ and the tubes were shaken vigorously for $1 \mathrm{~min}$. Then, the supernatant was filtered using $0.22 \mu \mathrm{m}$ syringe filters, and $500 \mu \mathrm{L}$ of the filtrate were transferred to a vial. The filtrate was evaporated close to dryness under a gentle nitrogen steam, reconstituted to $200 \mu \mathrm{L}$ PBS:EtOH $(7: 3, v / v)$ and subjected to the enzyme assay. The same samples were also analyzed using an accredited LC-MS/MS method [27] as a reference to the enzyme assay.

\subsection{Liquid Chromatography-Triple Quadrupole Mass Spectrometry Analysis}

A 1290 Infinity II LC system (Agilent Technologies, Santa Clara, CA, USA) coupled to a Triple Quadrupole G6495 (Agilent Technologies) mass spectrometer with electrospray ionization in positive ion mode (ESI+) was used for pesticide residue analysis. Dynamic multiple reaction monitoring (dMRM) mode was selected as operation mode. The separation took place in an Acquity UPLC HSS T3 analytical column $(100 \mathrm{~mm} \times 2.1 \mathrm{~mm}$ i.d. $\times 1.8 \mu \mathrm{m}$ particle size, Waters, Milford Massachusetts, USA) with controlled temperature at $40^{\circ} \mathrm{C}$, using water and $\mathrm{MeOH}$ (with the addition of ammonium formate and formic acid) as a mobile phase and a gradient described in [28]. The obtained data were processed using MassHunter software version B.07.00.

\subsection{Methods Validation}

The analytical performance of the AChE assay was fully evaluated in terms of repeatability, trueness and limits of detection (LODs). Strawberry and lettuce samples were spiked with carbofuran or carbofuran-3-hydroxy or dichlorvos. In the case of carbofuran, repeatability and trueness testing were performed in six-fold at two concentration levels $\left(0.020\right.$ and $\left.0.100 \mathrm{mg} \mathrm{Kg}^{-1}\right)$. Aliquots of the control extracts were used to prepare matrix matched calibration standards at $0.005,0.010,0.020$, $0.050,0.100,0.250$ and $0.500 \mathrm{mg} \mathrm{Kg}^{-1}$ for the enzyme assay. In terms of carbofuran-3-hydroxy and dichlorvos, repeatability and trueness testing were performed at 0.300 and $1.20 \mathrm{mg} \mathrm{Kg}^{-1}$ as they were weaker inhibitors compared to carbofuran. The calibration range was also different for these two compounds, in detail $0.078,0.150,0.300,0.600,1.20,2.5$ and $5.0 \mathrm{mg} \mathrm{Kg}^{-1}$. The LODs were calculated using the formula

LOD enzyme assay $=$ meanblank $-3.3 \times$ SDblank, $n=6$ blank samples 
To investigate the assay quantification capability in the presence of multiple residues, as well as to monitor their toxicity potential, the widely accepted toxic unit (TU) approach was applied in matrix matched calibration curves containing two analytes [29]. The calibration range for each analyte was based on the $\mathrm{IC}_{50}$ obtained in the matrix matched calibration curve. In detail:

- $\quad$ Three points below the $\mathrm{IC}_{50}$ value, $\mathrm{IC}_{50} / 8, \mathrm{IC}_{50} / 4, \mathrm{IC}_{50} / 2$;

- $\quad$ One at the $\mathrm{IC}_{50}$;

- $\quad$ Three points above the $\mathrm{IC}_{50}, 2 \times \mathrm{IC}_{50}, 4 \times \mathrm{IC}_{50}, 8 \times \mathrm{IC}_{50}$.

Moreover, a TU is the sum of the toxic contributions of each component in the mixture. The calculation formula for TU is the following:

$$
\mathrm{TU}=\mathrm{IC}_{50} \mathrm{~A}(\mathrm{mix}) / \mathrm{IC}_{50} \mathrm{~A} \text { (individual) }+\mathrm{IC}_{50} \mathrm{~B}(\mathrm{mix}) / \mathrm{IC}_{50} \mathrm{~B} \text { (individual), }
$$

where $\mathrm{A}$ and $\mathrm{B}$ are pesticides, $\mathrm{IC}_{50}(\mathrm{mix})$ is the effect of each component in the binary mixture and $\mathrm{IC}_{50}$ (individual) is the individually induced inhibitory effect, at the $\mathrm{IC}_{50}$ level. The TU model can inform about the joint inhibitory effect type, with TU equals to one meaning additive effect, in other words 0.5 TUA +0.5 TUB $=1$ TUA + B. Alternatively, TU $<1$ indicates synergistic effect whilst TU $>1$ shows antagonism between the inhibitors.

Finally, an accredited LC-MS/MS method was also applied for the same samples to compare the assay performance. Repeatability and trueness were also tested at the same conditions as for the enzyme assay and matrix matched calibration standards were prepared at $0.001,0.002,0.005,0.010$, $0.020,0.050$ and $0.100 \mathrm{mg} \mathrm{Kg}^{-1}$. The LODs were calculated using the formula.

$$
\text { LOD LC-MS/MS = SDregression/slope } \times 3.3 .
$$

\section{Results and Discussion}

As mentioned in the Introduction, the potential dietary intake of $\mathrm{CM}$ and/or OP residues poses a threat for human health due to their neurotoxicity. However, unless sophisticated laboratory instrumentation is available, then controlling residues is in most cases a rather difficult task. On this account, we focused on the development of a rapid, simple and cost-effective method capable to detect CMs and OPs in food matrices. In this study, critical assay parameters such as enzyme tolerance towards organic solvents (see Supplementary Materials), enzyme concentration and the enzyme substrate were optimized. In addition, AChE specificity towards 11 widely applied OP and CM pesticides was investigated since all these compounds have the same inhibitory mode of action. Based on this information, the assay was validated for carbofuran (a CM compound), carbofuran-3-hydroxy (a carbofuran toxic metabolite) and dichlorvos (an OP compound) in strawberry and lettuce using a fast and simple ethyl acetate extraction. Additionally, the AChE assay results were confirmed by an accredited LC-MS/MS method. Finally, the TU approach was applied to investigate the effect of mixtures containing two pesticide residues, as a simplified analogue towards real life conditions, since samples may be contaminated with multiple residues.

\subsection{AChE Assay Optimization}

\subsubsection{AChE Concentration and Substrates}

The suitability of conceivable substrates yielding color products [22-24] was considered. Comparing AThI:DTNB (Ellman's reagent), IDA and $\alpha$-NAc for AChE activity measurement, the lower the enzyme concentration the lower the obtained $\mathrm{IC}_{50}$; this shows the clear connection between enzyme activity and assay sensitivity. Importantly, Ellman's assay needed about 80 and 120 times less enzyme per well (compared to IDA and $\alpha$-NAc assays), indicating the higher affinity of AChE towards AThI (Ellman's assay substrate; Table 1). Regarding the total assay duration, it lasted from 15 (Ellman's and $\alpha$-NAc assays) to $45 \mathrm{~min}$ (IDA assay), depending on the assay used. Significantly, all assays were quite 
affordable, with the cost of the Ellman's assay being surprisingly low at about 0.16 euro per plate. Therefore, Ellman's assay was selected as it combined the best sensitivity with the least cost.

Table 1. Critical comparison of Ellman's, IDA and $\alpha$-NAc assays.

\begin{tabular}{|c|c|c|c|}
\hline Assay Characteristic & Ellman's & IDA & $\alpha$-NAc \\
\hline product color & yellow (412 nm) & blue $(670 \mathrm{~nm})$ & purple $(525 \mathrm{~nm})$ \\
\hline AChE activity, $\mathrm{U}_{\text {well }}{ }^{-1}$ & 0.009 & 0.75 & 1.1 \\
\hline total assay time & $15 \mathrm{~min}$ & $45 \mathrm{~min}$ & $15 \mathrm{~min}$ \\
\hline IC50 for dichlorvos, $\mu \mathrm{M}, n=9^{1}$ & $3.5(1.7-7.0)$ & $13(8.3-22)$ & $11(7.4-19)$ \\
\hline $\mathrm{IC}_{50}$ for carbofuran, $\mu \mathrm{M}, n=9^{1}$ & $0.099(0.092-0.11)$ & $0.27(0.22-0.36)$ & $0.23(0.18-0.31)$ \\
\hline cost, euro/plate & 0.16 & 14 & 22 \\
\hline
\end{tabular}

1: $95 \%$ confidence intervals in brackets.

\subsubsection{Studied CMs and OPs Inhibitory Strength and AChE Assay Specificity}

The inhibition potency of the studied pesticides largely differed, with carbofuran being the strongest inhibitor followed by chlorpyrifos-oxon and malaoxon (Table 2). Worthy to notice that the tested oxon forms (OPs with a $\mathrm{P}=\mathrm{O}$ moiety) were much stronger inhibitors compared to the thiono analogues (OPs with a $\mathrm{P}=\mathrm{S}$ moiety). This fact was expected due to the low sulfur electronegativity of the $\mathrm{P}=\mathrm{S}$ moiety resulting in low reactivity with the serine hydroxyl group at the active site of AChE. On the other hand, oxon forms $(\mathrm{P}=\mathrm{O})$ have relatively higher affinity for $\mathrm{AChE}$ active site compared to acetylthiocholine (Ellman's substrate), thus they undergo nucleophilic substitution reaction by serine hydroxyl group resulting in a covalent binding of a pesticide to AChE [30]. Regarding the oxidation, this physiologically takes part during the metabolism, probably by the mixed function oxidases (MFO), resulting in a stronger AChE inhibitor [31]. Except the oxidation, which can occur at the $\mathrm{P}=\mathrm{S}$ bond, also hydrolysis is possible [32], for example under acidic induced conditions resulting in phosphate ester hydrolysis and phosphoryl transfer [33]. Enzymatic hydrolysis of organophosphates also acts as a detoxification process exploiting various esterases and amidases depending the organism [34].

To assess AChE specificity towards carbofuran (the strongest AChE inhibitor), the cross-reactivity was calculated (Table 2). In the case of CM compounds, the cross-reactivity with aldicarb and carbaryl was less than $2 \%$ whilst with carbofuran-3-hydroxy (a carbofuran metabolite) was about $14 \%$ meaning that about 10-times higher concentration of carbofuran-3-hydroxy is necessary to achieve the same inhibition as in the case of carbofuran. Regarding chlorpyrifos, a widely used insecticide occasionally exceeding the EU maximum residue limits (MRLs) in various matrices, a very low cross-reactivity was calculated (about $0.024 \%$ ). Nevertheless, chlorpyrifos-oxon and malaoxon showed a significant cross-reactivity (about $45 \%$ and $25 \%$, respectively), which cannot be considered a problem for carbofuran detection in real food matrices because the $\mathrm{P}=\mathrm{S}$ bond is metabolically oxidized to $\mathrm{P}=\mathrm{O}$. In other words, chlorpyrifos-oxon and malaoxon forms cannot occur in plant crops. In terms of dichlorvos, paraoxon, malathion and parathion, the cross-reactivity was negligible ( $<3 \%$ in all cases). All in all, a minor cross reactivity was noticed only for carbofuran-3-hydroxy. 
Table 2. Inhibitory strength of tested CMs and OPs in terms of $\mathrm{IC}_{20}$ and $\mathrm{IC}_{50}$ and $\mathrm{AChE}$ specificity towards carbofuran in terms of cross-reactivity \%.

\begin{tabular}{|c|c|c|c|c|}
\hline Pesticide & Structure & $\mathrm{IC}_{20}, \mu \mathrm{M}^{1}$ & $\mathrm{IC}_{50}, \mu \mathrm{M}^{1}$ & Cross-Reactivity $\%$ \\
\hline carbofuran & & $0.037(0.033-0.041)$ & $0.099(0.092-0.11)$ & 100 \\
\hline aldicarb & & $2.1(1.1-4.0)$ & $6.1(4.4-8.5)$ & 1.6 \\
\hline carbofuran-3-hyrdoxy & & $0.25(0.20-0.30)$ & $0.72(0.62-0.83)$ & 14 \\
\hline carbaryl & & $2.1(1.1-3.7)$ & $6.2(4.5-8.5)$ & 1.6 \\
\hline chlorpyrifos & & $251(157-401)$ & $420(298-594)$ & 0.024 \\
\hline chlorpyrifos-oxon & & $0.081(0.050-0.13)$ & $0.22(0.16-0.30)$ & 45 \\
\hline dichlorvos & & $1.2(0.80-1.9)$ & $3.5(1.7-7.0)$ & 2.8 \\
\hline malaoxon & & $0.92(0.49-1.8)$ & $0.40(0.25-0.62)$ & 25 \\
\hline malathion & & $85(72-96)$ & $294(220-305)$ & 0.034 \\
\hline paraoxon & & $0.92(0.49-1.8)$ & $2.9(1.7-4.8)$ & 3.4 \\
\hline parathion & & $125(102-145)$ & 357 (330-395) & 0.028 \\
\hline
\end{tabular}




\subsection{Optimized AChE Assay Application in Lettuce and Strawberry}

As carbofuran was the strongest AChE inhibitor tested, it was chosen for assay performance demonstration in real life samples. Carbofuran screening is also important because despite being an unauthorized pesticide in the EU, it still remains a problem, which can potentially impact consumer's health. For example, carbofuran detection in goji berries from China resulted in the 2018 amendments of Regulation (EC) No 669/2009, which prescribes more frequent official controls at the point of entry into the EU territory [6]. During the latest European Pesticide Residue Workshop (EPRW) in 2018, carbofuran was detected in the so called "superfoods" such as goji berries and matcha tea [35], a group of "nutrient-rich" trending foodstuffs without a clear legal definition. Usually, these products are imported from countries where legislative regulatory mechanisms, requirements and official control systems are different than those in the European countries.

The assay was validated also for the detection of carbofuran-3-hydroxy (a carbofuran toxic metabolite, which is included also in carbofuran residue definition, https://ec.europa.eu/food/ plant/pesticides/eu-pesticides-database/public/?event=activesubstance.detail\&language $=E N \&$ selectedID=1082, last accessed 03/12/2019) and dichlorvos (an OP) since they share a common inhibitory effect against AChE (see Supplementary Materials). To investigate the cumulative inhibitory effect in food extracts, the TU approach was applied and matrix matched calibration curves containing two of the analytes were measured. Regarding the tested matrices, lettuce and strawberry were selected since they are crops in which carbofuran and dichlorvos were earlier reported to reach the toxicological reference value [36]. Another reason for selecting these matrices is their different composition mainly meaning different natural pigments transferred into extracts, which can potentially affect the AChE assay performance.

\subsubsection{Carbofuran Validation and Benchmarking}

Carbofuran analysis was successfully validated using the optimized AChE assay in lettuce and strawberry (Table 3). The obtained recoveries $(n=6)$ at two spiking levels, $0.020 \mathrm{mg} \mathrm{Kg}^{-1}$ and $0.100 \mathrm{mg}$ $\mathrm{Kg}^{-1}$, were higher than $70 \%$ in both matrices. Better repeatability was noticed in lettuce compared to strawberry and a LOD equal to $0.013 \mathrm{mg} \mathrm{Kg}^{-1}$ was achieved for lettuce and $0.012 \mathrm{mg} \mathrm{Kg}^{-1}$ for strawberry. Worthy to notice is that LODs do not allow us to determine the measurement of uncertainty and this is a reason why screening methods results need to be verified by instrumental methods. Other spectrophotometric AChE assays have also achieved LODs at the ppb level [20,21], however, insufficient validation was reported (solely focused on LODs). Comparing to EC methods, an AChE based EC sensor was utilized for carbofuran detection in cucumber achieving worse LODs than our study $\left(0.22 \mu \mathrm{M}\right.$ meaning $\left.0.048 \mathrm{mg} \mathrm{Kg}^{-1}\right)$ [37]. In another paper, a non-enzymatic EC sensor was used and lower LOD was reported for carbofuran residues in grape, orange, tomato and cabbage matrices [14]. However, such a sensor is not available at the market probably due to a complicated manufacture.

Although it was not feasible to achieve LODs lower than EU MRLs $\left(0.002 \mathrm{mg} \mathrm{Kg}^{-1}\right.$ and $0.005 \mathrm{mg}$ $\mathrm{Kg}^{-1}$ for lettuce and strawberry, respectively), the developed assay was able to detect carbofuran about two times lower than the Chinese MRL $\left(0.020 \mathrm{mg} \mathrm{Kg}^{-1}\right.$ for fruits and vegetables) [38] and ten times lower than the Indian MRL $\left(0.100 \mathrm{mg} \mathrm{Kg}^{-1}\right.$ for fruits and vegetables) [39]. Our method can enhance food testing in these countries, as carbofuran is commonly detected in foodstuffs originating from China [40] or India [41]. Additionally, the AChE assay can be used, in the EU, as a cost-effective pre-screening tool for imported food. Moreover, the developed method can be beneficial also for checking the EU acute reference dose (ARfD) exceedance. In detail, carbofuran ARfD is equal to $0.00015 \mathrm{mg} \mathrm{Kg}^{-1} \mathrm{Bw}^{-1}$ and the AChE assay could enable the concentration control that might, under certain consumption conditions, approach or even exceed it. Considering, e.g., an individual with a $70 \mathrm{~kg}$ body weight, the ARfD is $0.0105 \mathrm{mg}$, and then this value would be achieved when eating $150 \mathrm{~g}$ of a contaminated foodstuff containing $0.070 \mathrm{mg} \mathrm{Kg}^{-1}$ of carbofuran residues. In fact, such cases have been recently reported in the EU Rapid Alert System for Food and Feed (RASFF) portal (shorturl.at/quxKO, 
last accessed 10/01/2020). For example, carbofuran was detected at concentrations higher than $0.070 \mathrm{mg}$ $\mathrm{Kg}^{-1}$ both in eggplants and goji berries in Germany, Czech Republic and Switzerland the last two years.

To benchmark AChE assay analytical performance, the same strawberry and lettuce samples were analyzed by an accredited LC-MS/MS reference method (Figure 2). Recoveries $(n=6)$ at two spiking levels, $0.020 \mathrm{mg} \mathrm{Kg}^{-1}$ and $0.100 \mathrm{mg} \mathrm{Kg}^{-1}$, were higher than $80 \%$ in both matrices by using the Quick, Easy, Cheap, Effective, Rugged and Safe (QuEChERS) extraction. Although the QuEChERS extraction has been addressed as the golden standard for multiple residues extraction, an ethyl acetate extraction was modified for the AChE assay. In contrast to QuEChERS extraction, which includes several analytical steps, the developed ethyl acetate extraction, did not include any centrifugation step resulting in a faster extraction protocol. Another advantage was that ethyl acetate can be evaporated considerably faster compared to acetonitrile (QuEChERS solvent) due to a lower boiling point and thus a reduced extraction time was achieved. Furthermore, acetonitrile is related to difficulties associated with the removal of water molecules, therefore, ethyl acetate (a less polar solvent) fits better to the sample preparation simplification concept. Considering the LC-MS/MS method repeatability, it was significantly lower, less than $2 \%$, while LOD was equal to $0.0014 \mathrm{mg} \mathrm{Kg}^{-1}$. Comparing to the AChE assay, LC-MS/MS precision was fairly better and the LOD lower about one order of magnitude due to the highly selective and sensitive tandem mass detector.

Table 3. Carbofuran validation results in strawberry and lettuce for AChE assay and LC-MS/MS method.

\begin{tabular}{|c|c|c|c|c|c|c|c|c|}
\hline \multirow{3}{*}{$\begin{array}{c}\text { Method } \\
\text { Matrix } \\
\text { Spiking Level }\left(\mathrm{mg} \mathrm{Kg}^{-1}\right)\end{array}$} & \multicolumn{4}{|c|}{ AChE Assay } & \multicolumn{4}{|c|}{ LC-MS/MS } \\
\hline & \multicolumn{2}{|c|}{ Lettuce } & \multicolumn{2}{|c|}{ Strawberry } & \multicolumn{2}{|c|}{ Lettuce } & \multicolumn{2}{|c|}{ Strawberry } \\
\hline & 0.020 & 0.100 & 0.020 & 0.100 & 0.020 & 0.100 & 0.020 & 0.100 \\
\hline $\mathrm{R} \% 1$ & 91 & 94 & 71 & 78 & 79 & 91 & 81 & 88 \\
\hline $\operatorname{RSD}_{\mathrm{r}} \%{ }^{2}$ & 5 & 5.2 & 19 & 10 & 1.9 & 1.2 & 1.5 & 2.4 \\
\hline $\mathrm{LOD}\left(\mathrm{mg} \mathrm{Kg}^{-1}\right)$ & \multicolumn{2}{|c|}{0.013} & \multicolumn{2}{|c|}{0.012} & \multicolumn{2}{|c|}{0.0014} & \multicolumn{2}{|c|}{0.0012} \\
\hline
\end{tabular}

${ }^{1} \mathrm{R} \%$ : recovery $\% .{ }^{2} \mathrm{RSDr} \%$ : relative standard deviation under repeatability conditions \%.

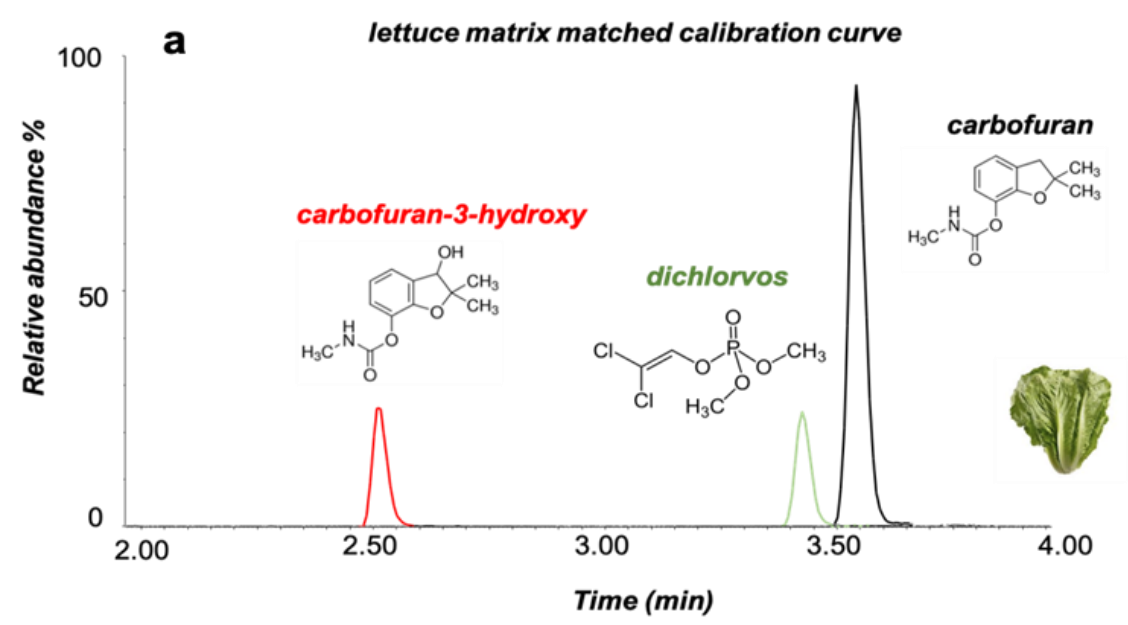

Figure 2. Cont. 


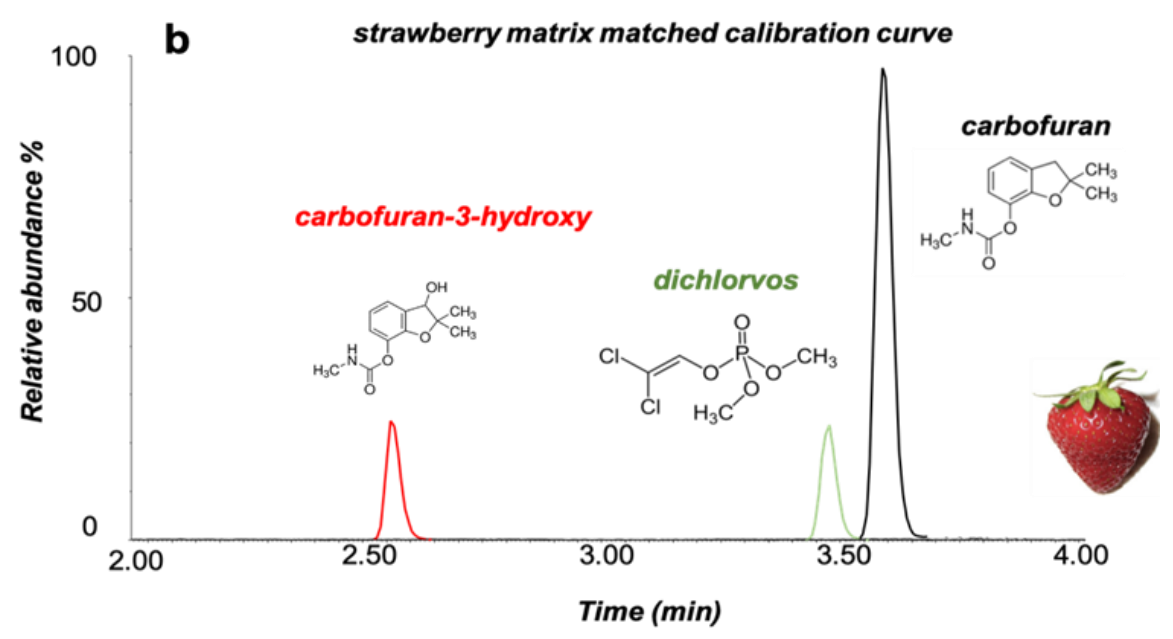

Figure 2. Extracted ion chromatograms (XIC) of carbofuran, carbofuran-3-hydroxy and dichlorvos at $0.020 \mathrm{mg} \mathrm{Kg}^{-1}$ in (a) lettuce and (b) strawberry matrix matched solutions using the LC-MS/MS system.

\subsubsection{TU Approach in Lettuce and Strawberry Extracts}

The co-occurrence of multiple pesticide residues in a single sample is not unusual indicating the need to evaluate their potential cumulative effect on the AChE assay. Actually, this topic has drawn EFSA interest, which recently published an opinion on cumulative risk assessment to pesticides affecting the nervous system [42]. In this way, mixtures containing two analytes (carbofuran, carbofuran-3-hydroxy or dichlorvos) were prepared in lettuce and strawberry blank extracts. The TU approach was applied and antagonism was noticed for all the binary pesticide mixtures in both matrices (Table 4). Important to notice is that in previous studies the cumulative inhibitory effect was evaluated only in buffers $[29,43]$. The presence of food matrix components in extracts may alternate the results of TU approach as synergistic effect was reported for a carbofuran-malathion mixture whilst mild antagonism for a carbofuran-chlorpyrifos mixture [29]. The cumulative effect may also vary in vivo, for example additive or synergistic effect was reported for salmon exposed to binary CM and/or OP mixtures [44]. In any case, implications related to pesticide cocktail effects should be considered carefully [45]. 
Table 4. $\mathrm{IC}_{50}$ for the tested binary mixtures in lettuce and strawberry extracts. TU were calculated as explained in Section 2.7 . TU $<1$, TU $=1$, TU $>1$ shows synergism, dose addition and antagonism, respectively.

\begin{tabular}{|c|c|c|c|c|c|c|c|}
\hline \multirow{2}{*}{ Mixture } & \multirow{2}{*}{$\begin{array}{l}\text { Matrix } \\
\text { Analyte }\end{array}$} & \multicolumn{3}{|c|}{ Lettuce } & \multicolumn{3}{|c|}{ Strawberry } \\
\hline & & ${ }^{1} \mathrm{IC}_{50}\left(\mathrm{mg} \mathrm{Kg}^{-1}\right)$ & ${ }^{1} \mathrm{IC}_{50} \operatorname{mix}\left(\mathrm{mg} \mathrm{Kg}^{-1}\right)$ & TU & ${ }^{1} \mathrm{IC}_{50}\left(\mathrm{mg} \mathrm{Kg}^{-1}\right)$ & ${ }^{1} \mathrm{IC}_{50} \operatorname{mix}\left(\mathrm{mg} \mathrm{Kg}^{-1}\right)$ & TU \\
\hline \multirow{2}{*}{$\begin{array}{c}\text { carbofuran }+ \\
\text { carbofuran-3-hydroxy }\end{array}$} & carbofuran & $0.055(0.038-0.078)$ & $0.046(0.014-0.14)$ & \multirow{2}{*}{1.70 (antagonism) } & $0.050(0.032-0.065)$ & $0.043(0.022-0.098)$ & \multirow{2}{*}{1.74 (antagonism) } \\
\hline & carbofuran-3-hydroxy & y $\quad 0.78(0.41-1.5)$ & $0.68(0.21-2.1)$ & & $0.85(0.55-1.8)$ & $0.75(0.32-1.7)$ & \\
\hline \multirow{2}{*}{$\begin{array}{c}\text { Carbofuran }+ \\
\text { dichlorvos }\end{array}$} & carbofuran & $0.055(0.038-0.078)$ & $0.041(0.021-0.080)$ & \multirow{2}{*}{1.50 (antagonism) } & $0.050(0.032-0.065)$ & $0.037(0.018-0.095)$ & \multirow{2}{*}{1.52 (antagonism) } \\
\hline & dichlorvos & $2.8(2.2-3.5)$ & $2.1(1.0-4.0)$ & & $3.2(1.8-3.0)$ & $2.5(1.2-4.7)$ & \\
\hline \multirow{2}{*}{$\begin{array}{l}\text { carbofuran-3-hydroxy + } \\
\text { dichlorvos }\end{array}$} & carbofuran-3-hydroxy & y $0.78(0.41-1.5)$ & $1.0(0.68-2.1)$ & \multirow{2}{*}{2.5 (antagonism) } & $0.85(0.55-1.8)$ & $0.95(0.75-3.0)$ & \multirow{2}{*}{2.14 (antagonism) } \\
\hline & dichlorvos & $2.8(2.2-3.5)$ & $3.8(2.9-4.8)$ & & $3.2(1.8-3.0)$ & $3.3(2.5-5.2)$ & \\
\hline
\end{tabular}

1: $95 \%$ confidence intervals in brackets. 


\section{Conclusions}

A quantitative spectrophotometric AChE assay for the studied CM and OP pesticides monitoring in lettuce and strawberry extracts was presented. Importantly, the AChE assay was validated in the food matrices and its performance was confirmed by an accredited LC-MS/MS, a practice commonly missing or mispresented in the available literature. The short analysis time (20 min for sample preparation/6 samples and $15 \mathrm{~min}$ for AChE assay) combined to the affordable cost (0.16 euro/96-microwell plate) showed that the AChE assay can be applied by laboratories with limited resources as a pre-screening tool. In contrast to chromatographic methods, which are serial meaning that only one sample is analyzed per run, up to 96 samples could be analyzed using the developed method achieving high-throughput. All in all, our contribution can be extremely useful for monitoring carbofuran in countries where this pesticide is still used or testing imports originating from those countries and a rapid answer is needed. Future work is under way to expand target analytes-food matrices portfolio and further improve LODs.

Supplementary Materials: The following are available online at http://www.mdpi.com/2076-3417/10/2/565/s1, Figure S1: AChE tolerance towards various organic solvents after $30 \mathrm{~min}$ of incubation with ethanol, methanol, acetonitrile and dimethyl sulfoxide $(n=3)$. The $100 \%$ AChE activity was set for $0 \%$ organic solvent in PBS., Table S1: Calibration ranges for each pesticide investigated for potential cross-reaction with carbofuran. $(n=7$ calibration points and one blank sample), Table S2: Carbofuran-3-hydroxy and dichlorvos validation results in strawberry and lettuce for AChE assay, Table S3: Carbofuran-3-hydroxy and dichlorvos validation results in strawberry and lettuce for LC-MS/MS method.

Author Contributions: Conceptualization, A.S.T., J.P., J.H.; methodology, A.S.T. and J.H.; software, A.S.T. and L.U.; validation, A.S.T., L.U., J.H.; resources, J.P. and J.H.; writing-original draft preparation, A.S.T.; writing一review and editing, A.S.T., L.U., J.P. and J.H.; supervision, J.H.; project administration, J.P. and J.H.; funding acquisition, J.P. and J.H. All authors have read and agreed to the published version of the manuscript.

Funding: This project has received funding from the European Union's Horizon 2020 research and innovation program under the Marie Sklodowska-Curie grant agreement No 720325, FoodSmartphone and the "National Programme of Sustainability I"-NPU I (LO1601-No.: MSMT-43760/2015).

Conflicts of Interest: The authors declare no conflict of interest. The funders had no role in the design of the study; in the collection, analyses, or interpretation of data; in the writing of the manuscript, or in the decision to publish the results.

\section{References}

1. Songa, E.A.; Okonkwo, J.O. Recent approaches to improving selectivity and sensitivity of enzyme-based biosensors for organophosphorus pesticides: A review. Talanta 2016, 155, 289-304. [CrossRef]

2. Karami-Mohajeri, S.; Abdollahi, M. Toxic influence of organophosphate, carbamate, and organochlorine pesticides on cellular metabolism of lipids, proteins, and carbohydrates: A systematic review. Hum. Exp. Toxicol. 2011, 30, 1119-1140. [CrossRef]

3. Patočka, J.; Cabal, J.; Kuča, K.; Jun, D. Oxime reactivation of acetylcholinesterase inhibited by toxic phosphorus esters: In vitro kinetics and thermodynamics. J. Appl. Biomed. 2005, 3, 91-99. [CrossRef]

4. $\quad$ Lin, J.-N.; Lin, C.-L.; Lin, M.-C.; Lai, C.-H.; Lin, H.-H.; Yang, C.-H.; Kao, C.-H. Increased risk of dementia in patients with acute organophosphate and carbamate poisoning: A nationwide population-based cohort study. Medicine (Baltimore) 2015, 94, e1187. [CrossRef]

5. Miao, Y.; He, N.; Zhu, J.-J. History and New Developments of Assays for Cholinesterase Activity and Inhibition. Chem. Rev. 2010, 110, 5216-5234. [CrossRef]

6. European Food Safety Authority (EFSA). The 2017 European Union report on pesticide residues in food. EFSA J. 2019, 17, e0573.

7. Brancato, A.; Brocca, D.; Ferreira, L.; Greco, L.; Jarrah, S.; Leuschner, R.; Medina, P.; Miron, I.; Nougadere, A.; Pedersen, R. Use of EFSA Pesticide Residue Intake Model (EFSA PRIMo revision 3). EFSA J. 2018, 16, e05147.

8. Tsagkaris, A.S.; Nelis, J.L.D.; Ross, G.M.S.; Jafari, S.; Guercetti, J.; Kopper, K.; Zhao, Y.; Rafferty, K.; Salvador, J.P.; Migliorelli, D.; et al. Critical assessment of recent trends related to screening and confirmatory analytical methods for selected food contaminants and allergens. TrAC Trends Anal. Chem. 2019, 121, 115688. [CrossRef] 
9. Rejczak, T.; Tuzimski, T. Recent trends in sample preparation and liquid chromatography/mass spectrometry for pesticide residue analysis in food and related matrixes. J. AOAC Int. 2015, 98, 1143-1162. [CrossRef] [PubMed]

10. Nelis, J.L.D.; Tsagkaris, A.S.; Zhao, Y.; Lou-Franco, J.; Nolan, P.; Zhou, H.; Cao, C.; Rafferty, K.; Hajslova, J.; Elliott, C.T.; et al. The end user sensor tree: An end-user friendly sensor database. Biosens. Bioelectron. 2019, 130, 245-253. [CrossRef] [PubMed]

11. Hua, X.; Eremin, S.A.; Liu, F.; Wang, M. Antibody Developments and Immunoassays for Organophosphorus Chemicals: A Review. Curr. Org. Chem. 2017, 21, 2640-2652. [CrossRef]

12. Karachaliou, C.-E.; Nikolaki, E.; Livaniou, E. Development of antibodies and immunoassays for carbamate pesticides. Curr. Org. Chem. 2017, 21, 2632-2639. [CrossRef]

13. Zhang, H.; Li, Z.; Snyder, A.; Xie, J.; Stanciu, L.A. Functionalized graphene oxide for the fabrication of paraoxon biosensors. Anal. Chim. Acta 2014, 827, 86-94. [CrossRef] [PubMed]

14. Wang, M.; Huang, J.; Wang, M.; Zhang, D.; Chen, J. Electrochemical nonenzymatic sensor based on CoO decorated reduced graphene oxide for the simultaneous determination of carbofuran and carbaryl in fruits and vegetables. Food Chem. 2014, 151, 191-197. [CrossRef]

15. Chen, D.; Sun, X.; Guo, Y.; Qiao, L.; Wang, X. Acetylcholinesterase biosensor based on multi-walled carbon nanotubes-SnO2-chitosan nanocomposite. Bioprocess Biosyst. Eng. 2015, 38, 315-321. [CrossRef]

16. Evtugyn, G.A.; Shamagsumova, R.V.; Padnya, P.V.; Stoikov, I.I.; Antipin, I.S. Cholinesterase sensor based on glassy carbon electrode modified with Ag nanoparticles decorated with macrocyclic ligands. Talanta 2014, 127, 9-17. [CrossRef]

17. Pundir, C.S.; Chauhan, N. Acetylcholinesterase inhibition-based biosensors for pesticide determination: A review. Anal. Biochem. 2012, 429, 19-31. [CrossRef]

18. Zhu, Y.; Li, M.; Yu, D.; Yang, L. A novel paper rag as 'D-SERS' substrate for detection of pesticide residues at various peels. Talanta 2014, 128, 117-124. [CrossRef]

19. Xia, N.; Wang, Q.; Liu, L. Nanomaterials-based optical techniques for the detection of acetylcholinesterase and pesticides. Sensors 2015, 15, 499-514. [CrossRef]

20. Pohanka, M.; Zdarova Karasova, J.; Kuca, K.; Pikula, J. Multichannel spectrophotometry for analysis of organophosphate paraoxon in beverages. Turkish J. Chem. 2010, 34, 91-98.

21. Yang, X.; Dai, J.; Yang, L.; Ma, M.; Zhao, S.-J.; Chen, X.-G.; Xiao, H. Oxidation pretreatment by calcium hypochlorite to improve the sensitivity of enzyme inhibition-based detection of organophosphorus pesticides. J. Sci. Food Agric. 2018, 98, 2624-2631. [CrossRef] [PubMed]

22. Ellman, G.L.; Courtney, K.D.; Andres, V., Jr.; Featherstone, R.M. A new and rapid colorimetric determination of acetylcholinesterase activity. Biochem. Pharmacol. 1961, 7, 88-95. [CrossRef]

23. Pohanka, M.; Hrabinova, M.; Kuca, K.; Simonato, J.-P. Assessment of acetylcholinesterase activity using indoxylacetate and comparison with the standard Ellman's method. Int. J. Mol. Sci. 2011, 12, 2631-2640. [CrossRef] [PubMed]

24. Marston, A.; Kissling, J.; Hostettmann, K. A rapid TLC bioautographic method for the detection of acetylcholinesterase and butyrylcholinesterase inhibitors in plants. Phytochem. Anal. Int. J. Plant Chem. Biochem. Tech. 2002, 13, 51-54. [CrossRef]

25. Sullivan, J.J.; Chen, Y.G.; Goh, K.S. Performance assessment and validation of a paramagnetic particle-based enzyme-linked immunosorbent assay for chlorpyrifos in agricultural runoff waters. J. Agric. Food Chem. 2007, 55, 6407-6416. [CrossRef]

26. Pihlström, T.; Blomkvist, G.; Friman, P.; Pagard, U.; Österdahl, B.-G. Analysis of pesticide residues in fruit and vegetables with ethyl acetate extraction using gas and liquid chromatography with tandem mass spectrometric detection. Anal. Bioanal. Chem. 2007, 389, 1773-1789. [CrossRef]

27. Kovacova, J.; Hrbek, V.; Kloutvorova, J.; Kocourek, V.; Drabova, L.; Hajslova, J. Assessment of pesticide residues in strawberries grown under various treatment regimes. Food Addit. Contam. Part A 2013, 30, 2123-2135. [CrossRef]

28. Drabova, L.; Alvarez-Rivera, G.; Suchanova, M.; Schusterova, D.; Pulkrabova, J.; Tomaniova, M.; Kocourek, V.; Chevallier, O.; Elliott, C.; Hajslova, J. Food fraud in oregano: Pesticide residues as adulteration markers. Food Chem. 2019, 276, 726-734. [CrossRef] 
29. Arora, S.; Balotra, S.; Pandey, G.; Kumar, A. Binary combinations of organophosphorus and synthetic pyrethroids are more potent acetylcholinesterase inhibitors than organophosphorus and carbamate mixtures: An in vitro assessment. Toxicol. Lett. 2017, 268, 8-16. [CrossRef]

30. Reddy, V.P. Chapter 2-Fluorinated Compounds in Enzyme-Catalyzed Reactions. In Organofluorine Compounds in Biology and Medicine; Reddy, V.P.B.T., Ed.; Elsevier: Amsterdam, The Netherlands, 2015; pp. 29-57. ISBN 978-0-444-53748-5.

31. Fukuto, T.R. Mechanism of action of organophosphorus and carbamate insecticides. Environ. Health Perspect. 1990, 87, 245-254. [CrossRef]

32. Lassila, J.K.; Zalatan, J.G.; Herschlag, D. Biological Phosphoryl-Transfer Reactions: Understanding Mechanism and Catalysis. Annu. Rev. Biochem. 2011, 80, 669-702. [CrossRef] [PubMed]

33. Ajilore, B.S.; Alli, A.A.; Oluwadairo, T.O. Effects of magnesium chloride on in vitro cholinesterase and ATPase poisoning by organophosphate (chlorpyrifos). Pharmacol. Res. Perspect. 2018, 6, e00401. [CrossRef] [PubMed]

34. Hoagland, R.E.; Zablotowicz, R.M. The Role of Plant and Microbial Hydrolytic Enzymes in Pesticide Metabolism; ACS Publications: Washington, DC, USA, 2001; ISBN 1947-5918.

35. Suchanova, M.; Schusterova, D.; Mraz, P.; Drabova, L.; Hrbek, V.; Stepan, R.; Kocourek, V. “Super foods"-Health promotion or risk? In Proceedings of the EPRW-12th European Pesticide Residue Workshop, Munich, Germany, 22-25 May 2018.

36. European Food Safety Authority. The 2016 European Union report on pesticide residues in food. EFSA J. 2018, 16, e05348.

37. Jirasirichote, A.; Punrat, E.; Suea-Ngam, A.; Chailapakul, O.; Chuanuwatanakul, S. Voltammetric detection of carbofuran determination using screen-printed carbon electrodes modified with gold nanoparticles and graphene oxide. Talanta 2017, 175, 331-337. [CrossRef]

38. Maximum Residue Limits for Pesticides in Food; Standards Press of China: Beijing, China, 2016; GB 2763-2016.

39. Food Safety and Standards (Contaminants, Toxins and Residues) Regulations; FSSAI: Delhi, India, 2011.

40. Zhang, C.P.; He, H.M.; Yu, J.Z.; Hu, X.Q.; Zhu, Y.H.; Wang, Q. Residues of carbosulfan and its metabolites carbofuran and 3-hydroxy carbofuran in rice field ecosystem in China. J. Environ. Sci. Health Part B 2016, 51, 351-357. [CrossRef]

41. Ramasubramanian, T.; Paramasivam, M. Persistence and metabolism of carbofuran in the soil and sugarcane plant. Environ. Monit. Assess. 2018, 190, 538. [CrossRef]

42. Crivellente, F.; Hart, A.; Hernandez-Jerez, A.F.; Bennekou, S.H.; Pedersen, R.; Terron, A.; Wolterink, G.; Mohimont, L. Establishment of cumulative assessment groups of pesticides for their effects on the nervous system. EFSA J. 2019, 17, e05800.

43. Arora, S.; Kumar, A. Binary combinations of organophosphorus pesticides exhibit differential toxicity under oxidised and un-oxidised conditions. Ecotoxicol. Environ. Saf. 2015, 115, 93-100. [CrossRef]

44. Laetz, C.A.; Baldwin, D.H.; Collier, T.K.; Hebert, V.; Stark, J.D.; Scholz, N.L. The synergistic toxicity of pesticide mixtures: Implications for risk assessment and the conservation of endangered Pacific salmon. Environ. Health Perspect. 2008, 117, 348-353. [CrossRef]

45. Rizzati, V.; Briand, O.; Guillou, H.; Gamet-Payrastre, L. Effects of pesticide mixtures in human and animal models: An update of the recent literature. Chem. Biol. Interact. 2016, 254, 231-246. [CrossRef]

(C) 2020 by the authors. Licensee MDPI, Basel, Switzerland. This article is an open access article distributed under the terms and conditions of the Creative Commons Attribution (CC BY) license (http://creativecommons.org/licenses/by/4.0/). 